This is an electronic reprint of the original article. This reprint may differ from the original in pagination and typographic detail.

Author(s): Aslam, Bilal; Karjaluoto, Heikki

Title: Digital advertising around paid spaces, e-advertising industry's revenue engine : A review and research agenda

Year: $\quad 2017$

Version:

Please cite the original version:

Aslam, B., \& Karjaluoto, H. (2017). Digital advertising around paid spaces, eadvertising industry's revenue engine : A review and research agenda. Telematics and Informatics, 34(8), 1650-1662. https://doi.org/10.1016/j.tele.2017.07.011

All material supplied via JYX is protected by copyright and other intellectual property rights, and duplication or sale of all or part of any of the repository collections is not permitted, except that material may be duplicated by you for your research use or educational purposes in electronic or print form. You must obtain permission for any other use. Electronic or print copies may not be offered, whether for sale or otherwise to anyone who is not an authorised user. 


\section{Accepted Manuscript}

Digital Advertising around Paid Spaces, E-Advertising Industry's Revenue Engine: A Review and Research Agenda

Bilal Aslam, Heikki Karjaluoto

PII:

S0736-5853(17)30224-1

DOI: http://dx.doi.org/10.1016/j.tele.2017.07.011

Reference: TELE 985

To appear in:

\section{Telematics and Informatics}

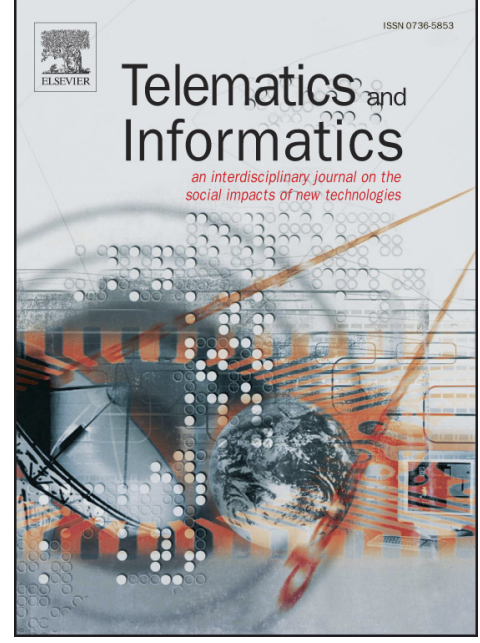

Received Date: $\quad 10$ April 2017

Accepted Date: $\quad 16$ July 2017

Please cite this article as: Aslam, B., Karjaluoto, H., Digital Advertising around Paid Spaces, E-Advertising Industry's Revenue Engine: A Review and Research Agenda, Telematics and Informatics (2017), doi: http:// dx.doi.org/10.1016/j.tele.2017.07.011

This is a PDF file of an unedited manuscript that has been accepted for publication. As a service to our customers we are providing this early version of the manuscript. The manuscript will undergo copyediting, typesetting, and review of the resulting proof before it is published in its final form. Please note that during the production process errors may be discovered which could affect the content, and all legal disclaimers that apply to the journal pertain. 


\title{
Digital Advertising around Paid Spaces, E-Advertising Industry's Revenue Engine: A Review and Research Agenda
}

\section{Bilal Aslam}

Jyväskylä University School of Business and Economics, P.O. Box 35, FI-40014 University of Jyväskylä, Finland

Email: bilal.m.aslam@student.jyu.fi

\author{
Heikki Karjaluoto
}

Jyväskylä University School of Business and Economics, P.O. Box 35, FI-40014 University of Jyväskylä, Finland

Email: heikki.karjaluoto@jyu.fi 


\section{Digital Advertising around Paid Spaces, E-Advertising Industry's Revenue Engine: \\ A Review and Research Agenda}

Authors: Bilal Aslam and Heikki Karjaluoto 
This Project has been funded by University of Jyvaskyla 


\section{Abstract}

We develop and describe a framework for research in a particular segment of digital advertising. Internet Advertising Paid Slots and Spaces (IAPS) is a neologism and work almost like a stock exchange for buying and selling advertising in various formats on designated spaces around web and make a significant contribution to Internet advertising revenues. These paid spaces were found to encompass diverse areas of Internet advertising that include search engine marketing, social media advertising and display advertising. Given the complexity of the modern digital advertising eco system, this literature review seeks to provide clarity, up-to-date knowledge and ongoing insights into Internet advertising channels, for managers making investment decisions in this context.

\section{Key words}

Digital advertising, Internet advertising, Social media advertising, Search engine marketing, Display advertising, Banner advertising

\subsection{Introduction}

With the creation of the World Wide Web and the Internet perhaps the most influential inventions since the printing press, the world has entered a new era (Hoffman, 2000). These technologies have radically transformed how companies do business, and especially the methods they use to increase awareness of their product and services. The advertising paradigm is now shifting from traditional advertising medium (TV, outdoor, direct marketing etc.) to more a digital-centric approach and advertisers are investing increasingly in digital at the expense of those traditional formats. The latest data show that this shift is accelerating more rapidly than expected, in the US where digital will takeover TV ad spending for the first time this year (eMarketer, 2016). Online video platforms have relative advantage in compatibility and ease of use, which decrease the likelihood of using television(Cha,2013)

But what accounts for this mass shift of paradigm? Internet advertising offers precise location-based targeting, and data-driven user's profiling, segmenting the target market according to preferences, likes and hobbies, as well as retargeting, easy interpretation of results, and more reasonable pricing models. These are unique attributes that are not offered by traditional media before; according to (Scott, 2010), companies that previously bought expensive advertising media like TV or outdoor advertising can now achieve more precise targeting at relatively lower cost.

Online advertising began in 1994, when the web magazine HotWired sold a banner ad to AT\&T and displayed the ad on its web page (Kaye and Medoff, 2001). Today, managers rely heavily on digital marketing to build their brand, taking the view that this approach also helps them to get to know their 
customers and to detect or anticipate negative client or market reactions (Tiag Verı'ssimo, 2014). Other benefits of digital marketing include the ease with which results can be tracked and monitored; rather than conducting expensive user research, managers can quickly view user response rates and measure the success of a marketing campaign in real-time, enabling more effective planning for the next campaign (busineszone, 2015).

However, it is important for managers to maintain an overview of this ever-changing field based on upto-date knowledge of the relevant literature. Digital advertising deploys different technologies, and diverse digital platforms in a convoluted eco-system of network players and new digital trends, which can hinder understanding. While existing literature reviews important digital technologies such as social media or search engine seeks to augment knowledge across broad subject area, it lacks clear boundaries to distinguishing different stream of relevant research.

The objective of the present literature review, then, is to attempt a synthesis of previous studies of digital advertising. In the interests of clarity, the review is built on well-defined boundaries and addresses only paid advertised web spaces appearing on laptops or desktops. This paid form of advertising, usually found in the upper, lower, or left side of a given webpage. By definition, this relates more to advertising than to marketing, as marketing can also include unpaid elements such as friend referrals or search engine optimization. To set these boundaries, the review summarizes the literature as a whole in different categories and then further expands on the results in each category to help managers to comprehend the complex ecosystem of digital advertising.

On this boundary when Authors expanded, they interestingly found that mostly paid digital advertising components consist of digital advertising spaces (IAPS) found around different areas of websites. IAPS on websites comprehensively covers almost all sections of digital advertising like e.g. search engine advertising, social media advertising or display advertising. From industry point of view; it's important because most of the digital advertising is happening in this paid form. For an example, social media giant Facebook, earns most of its revenues from digital display ads. According to (emarketer, 2016) Facebook will capture $\$ 10.29$ billion in display ad revenues in 2016 .

\subsection{Theoretical Background}

Within the more generic and broader term Internet marketing, this paper deals exclusively with Internet advertising - that is, any paid form of non-personal presentation or promotion of goods, services, or ideas by an identified sponsor (Kotler, 1984). Usually found in the upper, lower, or left side of a webpage, IAPS should not be confused with banner advertising, which is a domain within this broader category. This particular niche is an appropriate focus for research, as most of the academic literature centers on 
this particular area without naming it; from an advertising perspective, IAPS currently account for most of the industry's revenues.

\subsection{Research on Digital Advertising}

Since its inception in the 1990s, digital advertising (DA) has only recently attracted wide academic interest, with almost 68.5\% of the relevant research published in the last eight years (Nadia et al., 2013). No previous literature review has covered IAPS beyond generally discussing Internet marketing as a whole. Some industries are built on academic research; in the case of DA, it is the other way around.

In a review of the relevant literature from 1987 to 2000, Ngai (2003) identified 270 articles on Internet marketing, averaging 19 articles per year. From 2001 to 2004, an additional 639 such articles were published, representing an 843\% increase over the period 1987-2000 (Schibrowsky et al., 2007; Nadia et al., 2013). In another review, Corley et al. (2013) analyzed and classified a total of 411 articles and found that business models of internet marketing appeared in $41 \%$ of these. Other categories included the future of research strategies (4\%), the Internet advertising landscape (80\%), commercial exploitation of web 2.0 (16\%), and evaluation of online performance (9\%). Other important topics include online ethics, auction fraud, piracy, Customer Relationship Management (CRM) systems, marketing initiatives and financial performance, and Internet marketing architectures. In table 1, Nadia et al., 2013 depicted overall 75\% increase in no of publications as compared to previous decade (from 1993 to 2004) among various topics of Internet marketing.

Table1: Two decades of internet marketing research 1993-2012 (Source: Nadia et al., 2013)

\begin{tabular}{|c|c|c|c|}
\hline Topic Area & 004 & 2005-2012 & $\begin{array}{l}\text { Total Articles } \\
\text { Published }\end{array}$ \\
\hline Consumer Behavi & $218(24 \%)$ & $520(27 \%)$ & $738(26 \%)$ \\
\hline Social Media Networ & $9(1 \%)$ & $342(17 \%)$ & $351(12 \%)$ \\
\hline Internet Strategy & $208(23 \%)$ & $303(15 \%)$ & $511(18 \%)$ \\
\hline Communication & $163(18 \%)$ & $274(14 \%)$ & $437(15 \%)$ \\
\hline Business to Business & $60(7 \%)$ & $30(2 \%)$ & $90(3 \%)$ \\
\hline Product/brand & $16(2 \%)$ & $61(3 \%)$ & $77(3 \%)$ \\
\hline Distribuution & $49(5 \%)$ & $107(5 \%)$ & $156(5 \%)$ \\
\hline Pricing & $29(3 \%)$ & $90(5 \%)$ & $119(4 \%)$ \\
\hline Research Issues & $48(5 \%)$ & $63(3 \%)$ & $111(4 \%)$ \\
\hline Political Legal & $63(7 \%)$ & $96((5 \%)$ & $159(6 \%)$ \\
\hline others & $39(4 \%)$ & $71(4 \%)$ & $110(4 \%)$ \\
\hline Total & 902 & 1957 & 2589 \\
\hline
\end{tabular}

In the interests of more meaningful classification, the present review focuses specifically on Internet advertising (rather than marketing) as applied to laptops and desktops. It was decided that this kind of niche categorization is required because of the continuous inflow of new articles. 


\subsection{Research Methodology}

The search methodology for this review proceeds from the more general to the more specific - that is, from a broader to a more exact classification of the niche topic of Internet advertising. To this end, we searched both horizontally (e.g., Google Scholar) and vertically (e.g., ScienceDirect, SAGE, Wiley, Springer, Emerald, JSTOR, IEEE, Taylor \& Francis, Inderscience). We found that each academic journal tends to target some specific topic within the literature as a whole-for example, Marketing Science deals more with search engine marketing while the Journal of Interactive Marketing focuses more on display ads or the emergence of social media. It was therefore crucial to find the right balance among all these sources because (unlike previous literature reviews that discussed all areas of IM) we are specifically targeting the IAPS-related literature. In the first stage of the research, then, horizontal searches captured a bird-eye view of the whole topic; for comprehensive coverage, each journal's official website was also searched.

As is common practice for database searches, a keyword approach was used to identify previously published Internet marketing articles (Schibrowsky, 2007), using a combination of relevant search terms like Digital Advertising, Internet Advertising, Social Media Advertising, Search Engine Marketing/Advertising, Pay per Click, Display Advertising, and Banner Advertising. Again following Schibrowsky, the abstract of each article was then reviewed for proximity to DA, and the article itself was reviewed for its fit to our general domain boundary (i.e., IAPS). Because of the rapid changes in this field of research, we considered mainly articles from 2009 onward and only a few articles prior to that date. In addition, because of the interdisciplinary nature of this field, we searched for articles and conference proceedings like ICDE conference, KDE conference, KDD, ACM SIGKDD, ADKDD 13, WWW 2012 companions, and IEEE. During the vertical search, a number of related journals were consulted, including the Journal of Interactive Advertising, Telematics and Informatics, Marketing Science, Computers in Human Behavior, Electronic Commerce Research and Applications, International Journal of Advertising, Journal of Research in Interactive Marketing, and Machine Learning.

\subsection{Scope of the Research:}

As mentioned previously, this study deals explicitly with IAPS. For effective and comprehensive results, it was very important to define appropriate boundaries for the research domain. The review is also device-specific, considering only advertising on desktops and laptops and ignoring other devices like mobile phones. The included paid content can appear in different areas of a website. 


\subsection{Literature Classification and Framework}

Following analysis of the relevant literature, conference papers and other accredited streams of knowledge, certain similarities started to become evident in the content, and these informed the subsequent organization of the IAPS literature into three main categories: 1) search engine advertising, 2) display advertising, and 3) social media advertising. These three fields usually operate separately and are considered mutually independent in terms of initial set up, campaign costing and pricing, results, and network players. While the combined outcome contributes to a firm's overall advertising objective, it is worth noting that each component of the described model may contribute differently to the overall effectiveness of an advertising campaign (Figure 1). Because each component gives a different managerial yield, these domains can be deployed individually or collectively according to company requirements. The three essentials of these domains, then, are effectiveness diversity, mutual independence, and unique managerial yield, and their occurrence is the same for all three domains-in other words, all can be true for one specific domain. These domains comprehensively map previous work while at the same time drawing a visible boundary capturing only the relevant topic-related academic content. These background elements enhance the classification's practical viability and theoretical comprehensiveness.

The first domain (search engine advertising) deals with advertising slots that appear against targeted keywords on any search engine and is usually referred to as search engine marketing (SEM) or sponsored search advertising (SSA) (Agarwal, 2008; Nadia, 2012). In SEM, advertisers bid against targeted keywords through operational activities associated with participation in an auction: submitting the bid and ad copy, and customizing bids and ad copies according to various factors (Amaldoss et al., 2016). Much of the academic literature has been dedicated to this topic, and among the many competing search engines, Google is usually seen as the case company for research. 
Fig 1: IAPS, classification and details

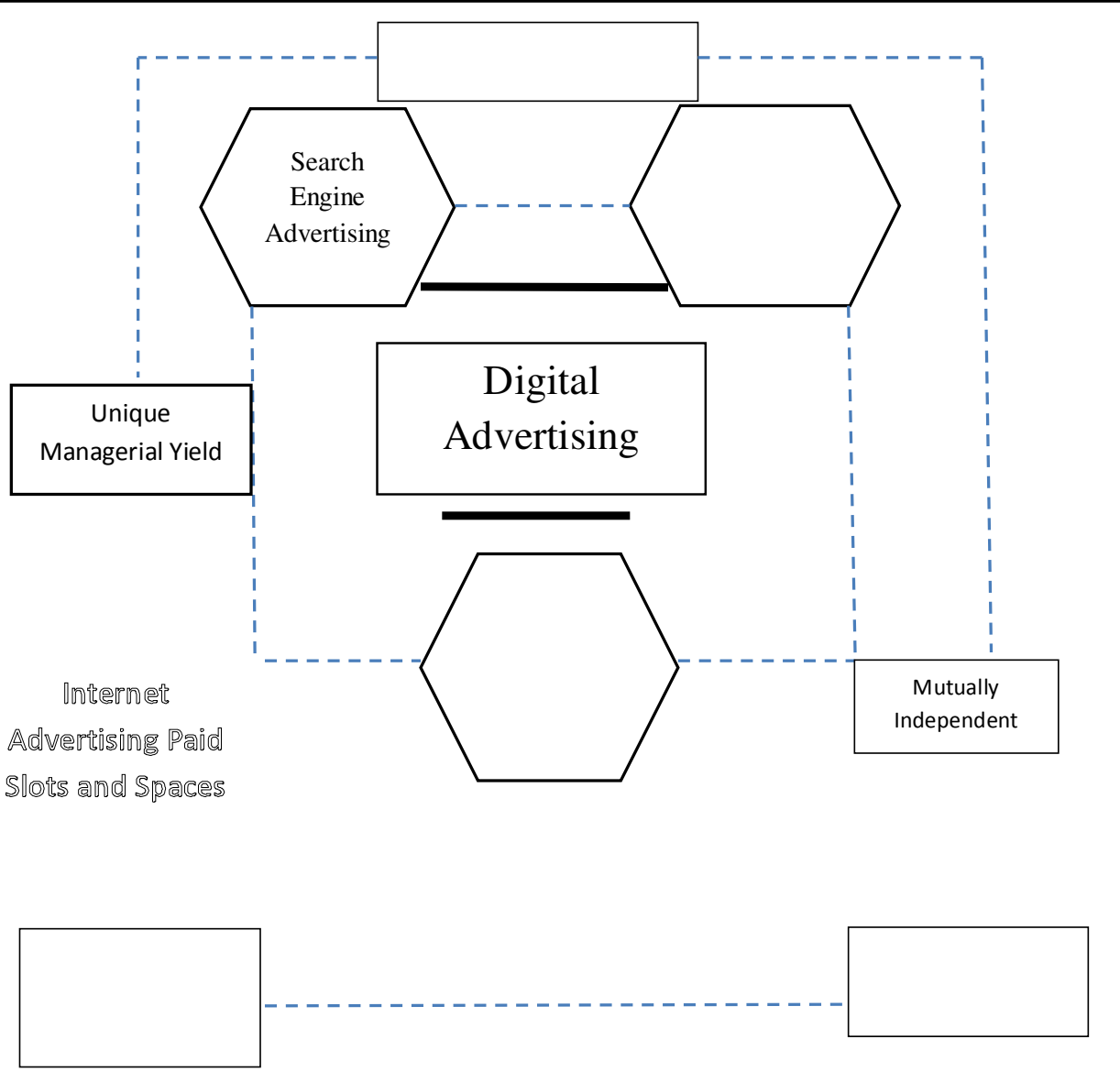

In the second domain (social media advertising), research on social media, and specifically on social network sites (SNS), remains at an embryonic stage (Michaelidou et al., 2011). With 1.86 billion monthly active users, Facebook has achieved huge popularity and, along with other major networks like Myspace, accounts for more than $80 \%$ of SNS ads. The managerial significance of this category is not sales or lead generation but branding attributes; indeed, many studies have noted the negative connotations of paid ads on social media.

The third domain (display advertising or banner ads) can be considered classical, having been there from the outset of Internet marketing. In this category, the publisher typically sells an ad (advertised slot on a web page) to the advertiser on the basis of impressions or clicks. Over time, the increasing number of players has made the display advertising ecosystem more complex. Key players include ad networks, demand-side platforms, supply-side platforms, and ad exchanges. All of these network players have 
evolved over time in response to the increasing complexity of buying and selling advertising spaces. Real-time (a.k.a. programmatic) buying is among the most recent developments in this field.

\subsection{Major Findings}

In total, 75 relevant publication (68 journal articles and 7 conference proceedings) were included in this review, sourced mainly from Elsevier and INFORMS, as well as from other key sources such as Emerald and the American Marketing Association (see Fig 3). Among the more than 30 journals consulted, most articles were taken from Marketing Science, Computers in Human Behavior, the Journal of Interactive Advertising, Telematics and Informatics and the International Journal of Advertising. Most of those articles (almost 94\%) were from the period 2009-2016.It was established that 30\% of the literature related to sponsored search advertising, $25 \%$ related to display ads, $19 \%$ related to social media advertising, and $7 \%$ related to general Internet marketing related topics.

In the domain of sponsored search advertising, the most important academic topics were the effects of different ad positions (Agarawal et al., 2011; Chan and Park, 2015; Naravanan and Kalyanam, 2015); agency compensation plans (Nadia et al., 2012); user click behavior (Kim et al., 2014); quality returns and optimal bids (Nadia, 2015; Nadia and Skiera, 2012); and attribution strategy and other keyword studies (Li et al., 2016; Jerath et al., 2014; Amaldoss et al., 2016; Shin, 2015; Rutz et al., 2011; Ji et al., 2010; Lu and Zhao, 2014; Luo et al., 2010).

For display ads, the main topics discussed in the literature were types of display advert; speed, animation and timing; type and content of ads yielding better performance (Andrea, 2011; Jacques et al., 2015; Rosenkrans, 2009; Kang Li et al., 2015; Brown, 2002; Wang et al., 2013); real-time bidding (Zhang et al., 2014; Yuan et al., 2013; Shalinda and Dutta, 2015); and retargeting (Bleier and Eisenbeiss,2105; Dalessandro et al., 2014).

As compared to the two other domains, social media advertising was found to be one of the newest and least researched topics. Important issues discussed in this domain included ad performance and engagement (Barreto, 2013; Mauver and Wiegmann, 2011; Hensel and Deis, 2010; Soares and Pinho, 2014; Knoll, 2016; Yang et al., 2016; Duffet, 2014); measuring social media ROI and content type (Hoffman and Fodor, 2010; Kim et al., 2014); Facebook consumer studies for better engagement and consumer attitude (Hansson et al., 2013; Boateng and Okoe, 2015; Zhang and Mao, 2016); and electronic word of mouth and branding (Lee et al., 2016; Kim et al., 2015). 


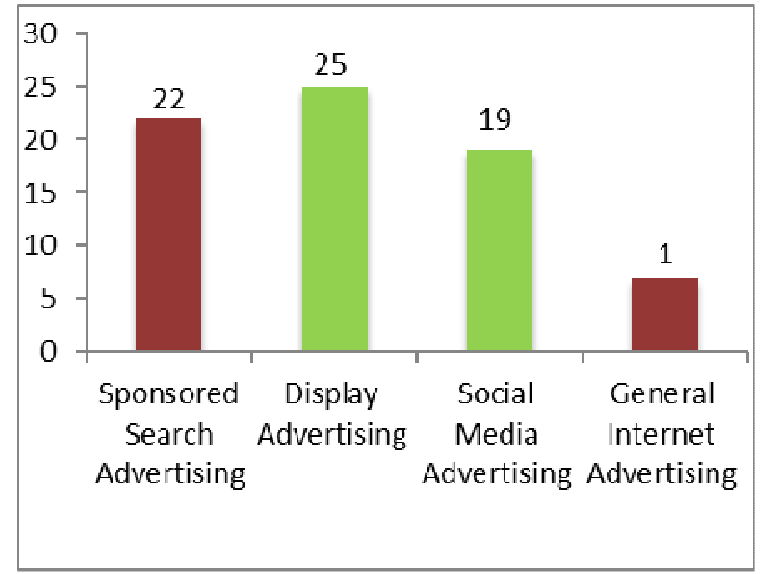

Fig 2: Number of articles in each domain

The distribution of articles across different domains is shown in Figure 2. Most of the articles relate to search engine advertising and display advertising while social media advertising occurs with least frequency. This is not unexpected, given the recent emergence of studies on this topic.

\subsection{Data Collection Methods}

The most widely used research methods in the reviewed articles were sponsored search data, experiments, questionnaires, and surveys (Figure 3). In general, the research methods used in each domain followed a similar pattern; studies of SEM relied mostly on data from a search engine, from an advertiser or third party website, or from an intermediary hired by the advertiser to manage campaigns on their behalf. These data would usually consist of search logs, keyword combinations, and results from previous campaigns. In the case of research on display advertising, surveys and questionnaires were the most commonly used techniques. Studies of SMA were found to use experiments, online surveys, and questionnaires. Some researchers collected data directly from category leaders such as Facebook or Google. In general, the data collection method reflects the kind of results researcher are looking for. For SEM, the most useful data are search logs, previously used keyword combinations, or results from previous campaigns, perhaps on different search engines. For display advertising or SMA research; on the other hand, experiments, surveys, and questionnaires are the more natural choice. 


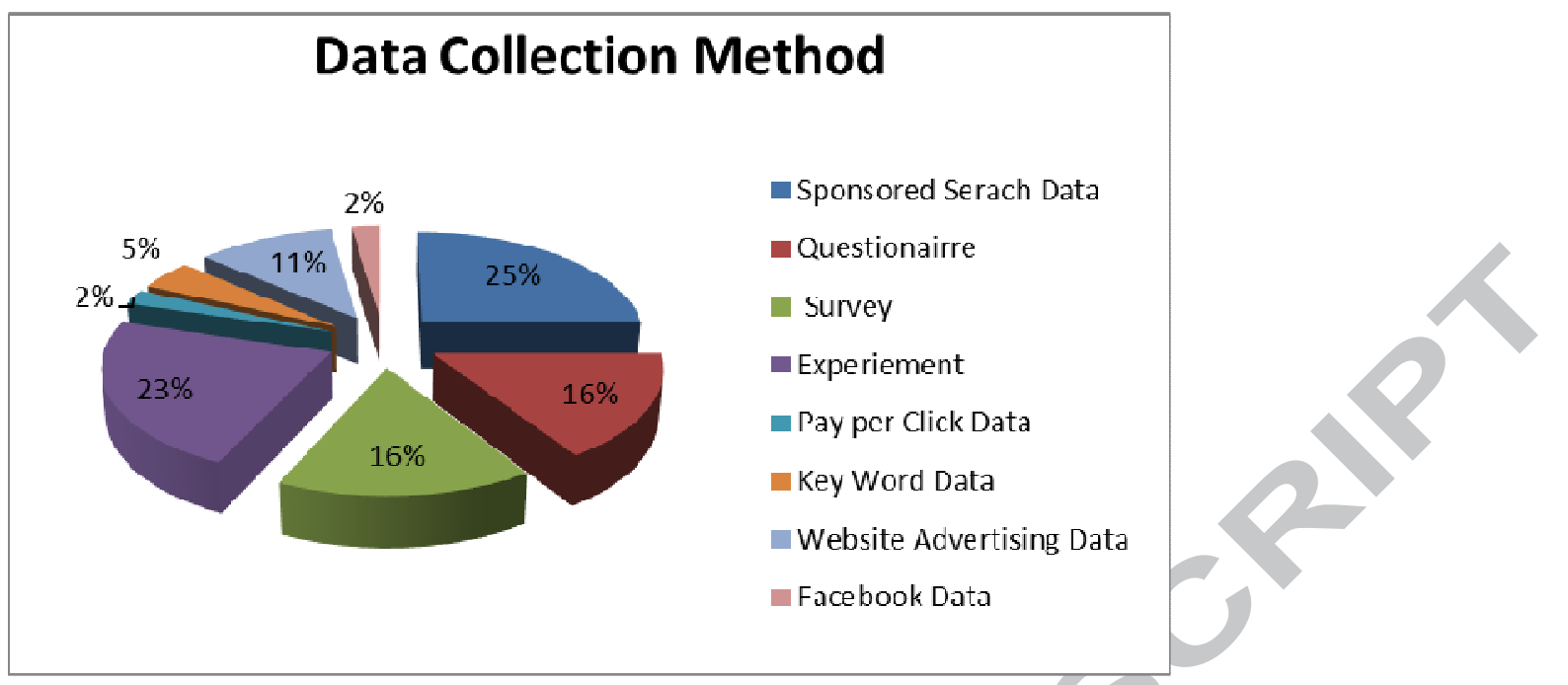

Fig 3: Data collection methods

\subsection{Detail Findings for Each Category/Domain:}

\subsubsection{Sponsored Search Advertising:}

Sponsored search advertising revolves around different stakeholders; including advertisers, users, and the search engine itself (see Figure 4). In line with the existing literature, we adopted Google as the standard search engine in studying sponsored search advertising as a whole; in reality, there are many search engines operating globally, with varying advertising mechanisms. To reach potential customers through paid search advertising, an advertiser needs to select the right keywords, write effective ad copy, and choose the relevant landing page. To capture all potential customers, there are usually multiple keywords (Li et al., 2016).

When a user enters a search query or simply types words into Google, the search engine returns organic and paid search listings or sponsored links. Unlike traditional products, digital content (e.g. organic search results) can be offered free because the marginal cost required for additional production is close to zero (Seoung Na et al., 2017).Users searching for more popular keywords are more likely to be satisfied by organic listings because they know exactly what they are looking for, and organic listings provide detailed information about the subject. On the other hand, those using less popular keywords are more inclined to click on sponsored search ads (Jerath et al., 2014), in which links are ranked sequentially. Figure 4 shows the general form of this process from advertiser to end user on Google's display ad network. Several advertisers can bid simultaneously for the same keywords; typically, Google uses a variant of what is called a second price auction, in which the buyer does not have to pay their full bid amount but only that of the next highest bidder. 


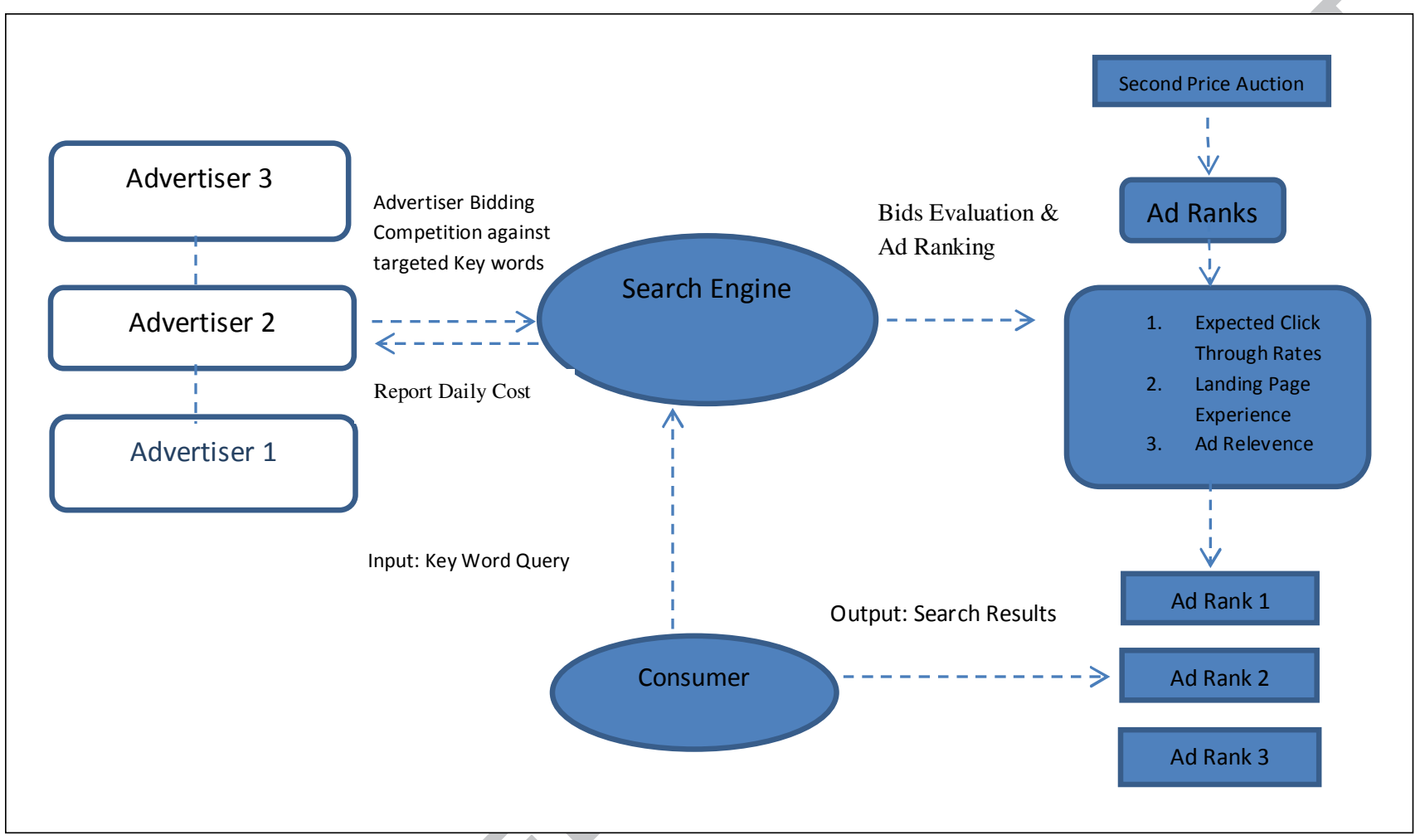

Figure 4: Sponsored search advertising overview

Google combines bids with multiple quality factors such as expected click-through rates (CTR), landing page and ad relevance, and expected impact of ad formats in calculating a score or rank for each ad (Google, 2014). Ranking and paid price against each click is determined by the second price auction model; search engines also estimate the quality of an advertisement against each keyword for sequential ranking (Nabout and Skiera, 2012). Ad ranking is considered to be of great importance, as consumers are more likely to click on high-ranked ads than on those listed further down (Feng et al., 2007). While this is the common understanding of search ranking systems, they may work differently in practice. Sometimes, there is no difference in terms of clicks and sales even if the advertiser moves up the ranking hierarchy. Where CTR and conversion increases with higher rank, price also increase; this is a tradeoff that advertisers need to evaluate carefully, and this is only possible when advertisers have credible estimates of the causal effect of position (Narayanan and Kalyanam, 2015). In the short run, advertisers seeking to maximize transactional benefits are often better off by placing less emphasis on attaining top positions (Agarwal et al. 2008). Similar arguments were made by Nadia and Skiera (2012) that better ranks likely lead to higher prices per click and higher costs for SEM, with ambiguous consequences for profit. 
Keyword selection also plays a major role in overall campaign effectiveness. Most keywords fail to generate reliable advertising impacts and exhaust the sponsor's advertising budget. Length of keyword is negatively related to CTR (Li et al., 2010), but long-phrase keywords usually help to increase ad rankings (at least initially). As users of specific keywords are not much affected by competition as compared to those using more general keywords, the use of specific keywords allows sellers to profit from consumers with concrete shopping goals by generating direct sales. On the other hand, general keywords can help sellers to profit from indirect sales (Lu and Zhao, 2014). However, bidding for all general keywords is not the right strategy, as managers need to carefully evaluate their consumers' search behaviors in noticing the product or brand (Nottorf and Funk, 2013).

Different search engines have solutions for better utilization of keywords. One such option is broad match, where the search engine runs advertiser ads when consumers search either for the exact keywords specified by the advertiser or for variations of those keywords, such as synonyms, singular and plural forms, and misspellings. CTR increase is roughly 50\% higher for exact match than for generic matching options (Klapdor et al., 2014). Broad match can help to reduce management costs, but interestingly, if major competitors start to use broad match, the advertiser's profits will decrease, creating a prisoner's dilemma (Amaldoss et al., 2016).

As some users begin from a more general search, most big companies and brands invest heavily in almost all related keywords. User search converts from general to branded search in what is known as the spillover effect (Rutz and Bucklin, 2011). The academic literature has only mentioned important factors like spillover and broad match, and detailed investigation is still pending; future research should investigate their exact nature and practical implications in more detail.

Longer and shorter key phrases in different ad positions can also have an effect. In this regard, Kim et al. (2014) introduced the concept of keyword attractiveness. They found that because words like free, great, and save are more attractive to users, advertisers can alter user click behavior in their favor by using these keywords. Their analysis also showed that attractiveness can explain user click behaviors in terms of enhanced relevance.

Advertisers commonly run many ads for the same link or website against multiple keywords or phrases. Usually, a customer will visit the website and leave but may well return by clicking another keyword link not previously clicked. If for instance on their third visit the customer actually buys the product, it is important to be able to attribute this conversion to a given keyword or phrase. This enables managers to understand which keywords provide more conversions and to use these more frequently in future. It is attributing the initial keyword responsible for conversion, known as attribution strategy. While Li et al. (2016) identified two main attribution strategies—first click and last click—Google offers other strategies 
such as last non-direct click, last ad words click, first interaction, linear, time decay, and position-based (Google.com)

\subsubsection{Social Media Advertising}

Social media advertising is a relatively newer topic. Through social media, it is possible for companies of all sizes to achieve marketing and branding goals at lower cost. Social media is used for various purposes in organizations, such as advertising and promotion, branding, information search and especially in building customer relation and other customers service activities (Parveen et al., 2015).The main players in social media advertising include Twitter, LinkedIn, Instagram and Facebook. User use these platforms for various factors, like snapchat is more used for pastime, sharing problems, and improving social knowledge, while Instagram users like to follow fashion and have the highest brand community engagement. Twitter users had highest brand community identification and membership (Phua et al ., 2017) . IAPS constitute a major source of revenue for any SNS specially for Facebook. People (especially Millennials) spend a lot of time on Facebook; one survey confirmed that nearly six out of ten Millennials spent one hour or less on Facebook per log-in session, which undermines marketing communication efforts (Duffett, 2014)

Social media differs significantly from sponsor search advertising. In the latter, a user shows a strong interest in a subject by entering the appropriate keywords before encountering any paid or organic results. In social media settings, however, users often have no intention of buying a product or service, as they are more likely to be interested in connecting with their friends and family. For this reason, the typical process of buying and selling does not fit as exactly here as in the other two categories of IAPS. Some authors advocating social media advertising systems were found to emphasize the soft benefits for advertisers in terms of building an information network or brand building. Paired comparisons indicated that users more readily accept virtual brand communities than Facebook advertising and respond more favorably to them. As well as placing more trust in virtual brand communities, Facebook users also consider them less irritating (Chi, 2016). The purpose of social media should be to enhance business branding by offering preferred customers direct communication with the brand, and businesses therefore need to facilitate social media inputs (Hensel et al., 2010).

However, as paid listings (IAPS) are a major source of revenue for any social media site, it must be acknowledged that this is very powerful medium for marketers seeking to target people according to their preferences. A majority of users do not see Facebook as an information source, nor do they purchase products because of Facebook; users of these social sites spend time there primarily for fun or digital socialization. In this frame of mind, they are less likely to be favorably disposed to direct advertising, as one of the benefits of social networks is to escape from the overflow of ads on other sites (Maurer, 2011). There is evidence that users tend to avoid advertising in SNS for a number of reasons: to protect their 
privacy or because they have had negative experiences, consider it irrelevant, or are skeptical about advertising persuasion in social media (Hoy and Milne 2010; Kelly et al., 2010).

Consumers do not trust the information acquired from online social networking sites (Kelly et al., 2010). However, Facebook ads perform better when they include written or graphical content (as compared to motion video). This may be because the current Facebook interface supports pictures and text better than motion videos (Kim et al., 2015).

In contrast, studies by Boateng and Okoe (2015) have established that people have a positive view of SNS advertising and corporate or brand names play an important role in its acceptability. For managers, the best strategy is to maintain a balance, offering consumers quality information rather than quantity (Hansson et al., 2013). Barreto (2013) also found that advertising that truly engages the customer is more likely to be accepted on social media sites and is more powerful than banner ads. Advertisements displayed on SNS provide entertainment and information content or impressions, increasing the advertisements worth (Saxena and Khanna, 2013) and making it advantageous to increase the congruity of ads on social media to the customer's ongoing interests and discourse. For example, if a Facebook user is discussing buying shoes, an advertiser can monitor the newsfeed to identify the user's end purpose-if, for instance, it is for a school party, it makes sense to display fashionable, trendy shoes to this particular user. If a user employs social media for connection and relationships, the ads should be designed to capture this, displaying ads about social events, movies, and books rather than an ad that sells a product (Zhang and Mao, 2016). Advertising in online social networks (OSNs) is more useful than targeting individual persons, as group intention can create a sudden interest toward a particular product (Soares and Pinho, 2014). It is important to know how exactly to target OSNs by considering all relevant factors, including practicality, cost, price, and (most importantly) returns. OSNs can also be a double-edged sword; if a group's likes increase an ad's creditability then its dislikes will adversely affects that creditability. Research on the core advertising aspects of social media lacks an industry perspective, as studies tend to focus on user attitudes and perceptions, and there is no systematic empirical overview (Knoll, 2016). Measuring the performance of a social media campaign is also very different; the worst outcome represents is no engagement with the campaign, but this is not exactly true of social media, as the rules of engagement are very different for SNS (Hoffman and Fodor, 2010).

\subsubsection{Display Advertising}

This category is considered classical, in that Internet advertising has its roots in display advertising. In this context, it is important to distinguish between sponsored search ads and display ads. The latter are placed in the websites that consumers browse, and it does not matter from where they are linked. In contrast, search engine advertising displays on the result page when a user enters a keyword query. As discussed earlier, the user shows a prior interest in a particular subject by entering their desired keywords. Secondly, while the structure of search engine ads is normally standardized in the form of text with web 
links, and the advertiser has little control over its design and layout, display ads come in various sizes and may differ in content orientation (Luo et al., 2011).

Banner ads are typically found at the top of a web page in a horizontal rectangular format. Other formats include skyscraper, which refers to a rectangular-shaped ad whose height exceeds its width and is vertically positioned along the side of a webpage. These skyscrapers tend to grab more attention than horizontal banners because they are closer to the information-rich task area than horizontal banners (Kuisma et al., 2010). As display ads enable customization of ad format, duration, content, and occurrence, researchers have tried to find the appropriate balance between these key factors in the interests of better attention and therefore better results. This variety can make an ad complex or easy to comprehend; if a banner ad is difficult to process, an increase in time duration can positively affect user attitude because there is more time to process complex information. On the other hand, if an ad is easily processed, this may first enhance and then undermine respondent attitude, following a U-pattern (Wang et al., 2013). Rich formats like flash animation are considered more attractive than a static banner ad; an animated ad does not initially attract attention, but with repeated short exposure, animated ads achieve better results than static ads (Lee et al., 2013). Animation also has a positive effect on attention to skyscrapers but impacts negatively on attention to banners (Kuisma et al., 2010). Rich media interactive ads (motion video) are another type of display advertising that engages users and captures high levels of user interactivity (Rosenkrans, 2009). Some banner ads that come with a pulldown menu score better on attention than static banners primarily because this offers the user a unique format and greater information appeal (Brown, 2002).

The effectiveness of display ads is easier to understand if we also take account of the product itself, in terms of low or high involvement. While high-involvement ads fare better with rich media formats, lowinvolvement product ads are more successful when text-based (Flores et al., 2013). These ads should be placed according to the website's content-for example, sports-related products should be advertised in the sports pages of a newspaper.

\subsubsection{Realtime Bidding: Future of Display Ads}

As display advertising is one of the oldest Internet marketing tools, its ecosystem has become complex because many players now contribute to its different stages. It is also a challenging system because data flows (from advertiser to consumer) can involve dozens of different corporate players (Perlich et al., 2014). The introduction of real-time bidding (RTB) (a.k.a. programmatic buying), which allows bidding on a display ad impression as it is generated, means that the display advertising landscape is changing rapidly. Before the emergence of $\mathrm{RTB}$, the display advertising market was mainly divided into premium contracts and ad networks (Yuan et al., 2013). RTB differs fundamentally from sponsored search auctions, which involves bidding against selected keywords (Zhang et al., 2014). 


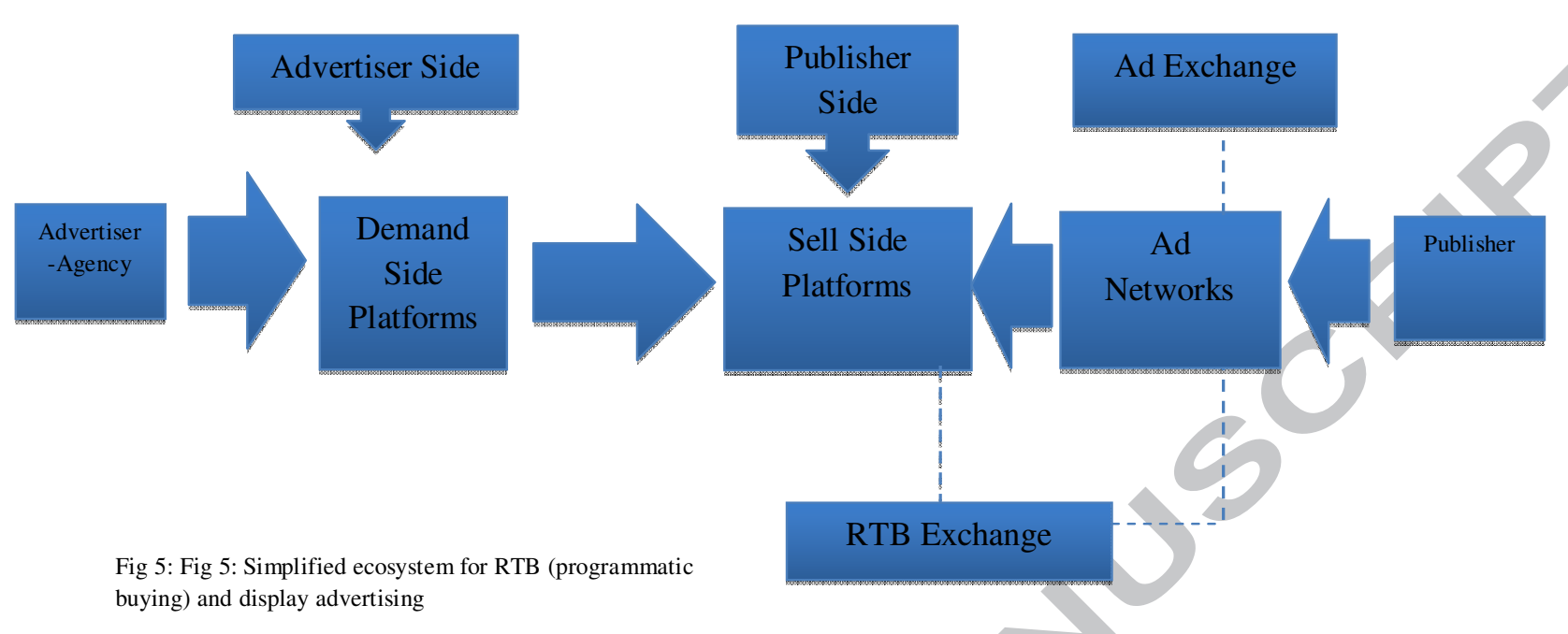

Fig 5: Fig 5: Simplified ecosystem for RTB (programmatic

buying) and display advertising

The RTB process commences when an advertiser requests a demand-side platform (DSP) to run an ad campaign that meets their requirements in terms of budget, target audience, and duration. When the user visits the publisher website, the web browser or mobile app sends the user's preferences, contact details, and location to the publisher. The publisher will check whether the contracted advertiser is available; if not, the ad request is sent to RTB exchange or supply-side platforms, which then create a bid request and send this to all DSPs. The RTB exchange will decide the bid price based on an ad agency request and sends this information to the particular RTB exchange. The RTB exchange decides the winning bid after some specified time and notifies the winning DSP, which then requests the ad from ad agency and sends to RTB exchanges to be sent to the publisher for final display to the user (Adikari and Dutta, 2015). In short, RTB allows an advertiser to buy an impression as it is created.

\subsection{Discussion}

In the IAPS literature, digital advertising around was found to be divided into three main categories: search engine advertising, display advertising, and social media advertising, all of which use and sell advertising spaces or IAPS. These categories are mutually independent; from an industry point of view, campaign mechanics, payment method, audience selection, and results differ across categories, with different managerial yield.

In the case of SEA, previous studies have focused on keyword selection, bidding strategy, and search engine ad ranking systems. With keywords and advertiser bidding strategy as inputs, the search engine provides output to the desired audience in terms of sequential ranking, using the second price auction 
model (Nabout and Skiera, 2012). From an advertiser perspective, it is crucial to bid on the right keywords. Defining the advertiser keyword strategy depends on many factors, including target market, nature of the business, and analysis of data from past campaigns. Keyword selection also plays a major role in overall campaign effectiveness, as most keywords do not generate reliable advertising impacts and exhaust advertising budgets ( $\mathrm{Li}$ et al., 2010). According to the literature, advertisers need to decide whether to use long-tail keywords, general keywords, or keywords with a buzz factor (e.g., attractive keywords like sale, free, or save) (Kim et al., 2014). Whether using broad match or exact match, they must determine the most appropriate ad rank and related keywords.

The current literature blurs the distinction between general and attractive keywords. As bidding on attractive keywords can increase CTR for exact match, advertisers can benefit from a more focused approach to keywords in terms of its target audience and its product. On the other hand, broad match can help to reduce management costs, but if major competitors start to use broad match, this reduces the advertiser's profits and creates a prisoner's dilemma (Klapdor et al., 2014). Big companies that bid for all kinds of words normally benefit from the spillover effect; the customer may start out from basic research, with no particular idea about the brand, later shifting to brand-related research because the desired product is associated with that particular brand (Rutz and Bucklin, 2011).

The scarcity of academic studies on social media in relation to IAPS hinders nuanced understanding. Much of the available literature reports unfavorable responses to social media advertising in social networks (Maurer, 2011) because of privacy concerns or a lack of relevance, as well as skepticism about persuasion (Hoy and Milne, 2010; Kelly et al., 2010). Certainly, users spend time on social media for purposes other than looking at ads (Maurer, 2011). However, social media networks like Facebook earn most of their revenues from advertising, and principally from IAPS, in a variety of forms that include App Engagement, App Installs, Brand Awareness, Clicks to Websites, Event Responses, Lead Generation, Local Awareness, Offer Claims, Page Likes, Page Post Engagement, Store Visits, Video Views and website conversions (Facebook.com).

It's very important to connect with user in a way that they are not offended by the advertised content, so paid content should be integrated to become part of the community, creating a connection between user needs, peer approval, and the advertisement. "Content is king;" certainly, this is true for social media. Without great and appealing content, one's voice cannot be heard above the noise of social media marketing.

The mechanics of display advertising were simple at the outset: buying and selling of spaces on different websites as a direct transaction between publisher and advertiser. But as time passed, more and more players emerged: demand-side platforms, supply-side platforms, ad exchanges, and ad networks. RTB , which facilitates bidding on a display ad impression as it is generated, is very different from Sponsored 
Search Advertising, where they bid on selected keywords (Zhang et al., 2014). RTB is also known as programmatic buying, which means that every online ad impression can be evaluated, bought, and soldall individually, and all instantaneously. Enabling exchanges and buyers to work systematically together to sell and bid on ads, it means that every impression can be cost effective and placed in front of the right person at the right time (Green, 2012). This is the future of all online display advertising.

\subsection{Limitations}

The first limitation of the present study is its device specificity; as a basic research premise, we considered only Internet advertising on desktops or laptops, excluding mobile devices in the interests of clear classification of the literature. From an industry perspective, the introduction of smart phones has made it easy for users to perform the same basic functions that were previously possible only with desktops or laptops. Now, users can check and reply to email messages, and there are mobile applications for mainstream websites like Facebook and Google. As more people switch to mobile, companies are investing more in mobile advertising than ever before, and this trend will continue to grow in the years ahead. For that reason, another review on mobile advertising in future can offer a broader perspective.

Secondly, we favored the term "advertising" over "marketing," as advertising is generally taken to mean paid or consciously initiated by a company, either directly or through intermediaries. For clearer results, we have included only paid advertising spaces (IAPS) that may appear on any website, search engine, or social media site. While this has helped us to effectively segregate the literature, it also somewhat limits the view of digital advertising on the macro level. A company can adopt other important paid initiatives such as email marketing, blogging, and search engine optimization, but by considering only defined advertising spaces around the web, those other components of digital advertising were excluded from our research.

Video advertising has seen tremendous growth in recent years, and eMarketer (2016) expects US digital video ad spending to see double-digit growth annually through to 2020. While Facebook and others can be seen as strong contenders in the video space, YouTube remains the go-to platform for about threequarters of brands engaging in digital video advertising. Stats show that extended use of video tools has increased the online video culture in social networks (Penni,2016)

Online video culture is on the increase as the statistics showed that the extended use of video tools have become part of the social capital and the intensity of social network use

This kind of advertising can take many forms, as for example at the start or in the middle of a YouTube video. Again, the basic premise of this research did not extend to the full range of video advertising, and further studies are needed in this niche. 
Although the present study aimed to review all studies of relevance to digital advertising and searched a broad range of keywords, we cannot be sure that the selected articles represent the full range of relevant research. It is possible that some articles related to social media advertising were not captured by the search terms, and other relevant articles may not have appeared in the chosen databases.

\subsection{Future Research Directions}

This paper has identified many new dimensions for possible future research, either on the broad foundation of the current findings or through further investigation within each domain. At the broader level, it will be important to properly establish the classification of domains of Internet advertising for mobile devices, as mobile advertising spend is increasing rapidly. It will also be important to see what happens when boundaries are removed and the current research is extended in scope. So far, we have studied Internet advertising only in relation to IAPS, which has helped to better classify the literature. However, removing this boundary (and others like that between marketing and advertising) should yield interesting and more comprehensive findings.

Our domain-related findings also highlight important directions for research. First of all, most of the many important studies relating to search engine advertising dealt primarily with optimal bid prices, keyword selection, and ranking priorities under various circumstances. It is intriguing to see the algorithmic effects of a search engine on SEA. For instance, Google changes its algorithm regularly, and while most of the changes directly affect organic search listings, there may also be indirect impacts on paid advertising. Indeed, any algorithmic change in organic search can also affect paid search. This becomes more important when Google changes Rank Brain—an artificial intelligence system it uses to monitor search results, making changes where necessary and ultimately guiding the development of their core search algorithm (Forbes, 2015).

Most of the existing studies related to social media advertising have neglected paid advertising content. Instead, social media is seen as more appropriate for brand building and other indirect marketing methods on the basis that because the purpose of social media is fun, interaction, and related personal elements, any direct corporate interference or commercial activity would be viewed negatively by the user. This may be logically correct, but analysis of revenue streams for social media reveals that selling paid content tops the list. In short, companies favor paid content on social media because it yields the desired results, perhaps because companies are targeting users at the right time and place, as in online social networks. As this will not necessarily be viewed negatively by users, further exploration of paid content in social media offers new avenues of research. 
Real-time bidding (or programmatic buying) is a key topic in the future of display advertising, including more detailed research on improving efficiencies and optimal biddings. Retargeting is one aspect of RTB that also warrants further research to explore different retargeting methods and operational running feasibilities for different companies. In general, further empirical investigation of RTB is critical for accessing its different advertising dimensions.

\subsection{Conclusion}

Studies of Internet advertising are still in their infancy. The present research is unique in that no previous literature review has dealt specifically with IAPS (Internet Advertising Paid Slots/Spaces). This paid form of internet advertising, usually found in the upper, lower, or left side of website, social media, or search engine pages, should not be reduced to banner advertising, which is just one instance of this broader domain. No previous literature review has specifically addressed Internet advertising that includes only paid listings/content appearing only on laptop or desktop devices. It is interesting to note that IAPS comprehensively maps the academic literature primarily because most Internet advertising centers on this particular area without naming it. From an advertising industry perspective, these slots account for most of the industry's revenues. Under IAPS, we have identified three relevant domains: sponsored search advertising; 2) social media advertising; and 3) display advertising.

\section{References}

1. Abubaker Shaouf, Kevin Lü , Xiaoying Li (2016), 'The effect of web advertising visual design on online purchase intention: An examination across gender', Volume 60, July 2016, Pages 622634, http://dx.doi.org/10.1016/j.chb.2016.02.090

2. Alexander Bleier, Maik Eisenbeiss (2015), 'Personalized Online Advertising Effectiveness: The Interplay of What, When, and Where', Marketing Science 34(5):669-688. http://dx.doi.org/10.1287/mksc.2015.0930

3. Search Engine Land (2016), 'All About The Changes To Google's Ad Layout On Desktop Search Results .A look at what is changing and what is not on Google desktop search results' http://searchengineland.com/243057-243057

4. Ana Margarida Barreto, (2013), 'Do users look at banner ads on Facebook?', Journal of Research in Interactive Marketing, Vol. 7 Iss 2 pp. 119 - 139.Permanent link to this document: http://dx.doi.org/10.1108/JRIM-Mar-2012-0013 
5. Ana Maria Soares, José Carlos Pinho (2014) 'Advertising in online social networks: the role of perceived enjoyment and social influence', Journal of Research in Interactive Marketing, Vol. 8 Iss: 3, pp. $245-263$

6. Anant Saxena ,Uday Khanna (2013), 'Advertising on Social Network Sites: A Structural Equation Modelling Approach', Vision 17(1) 17-25

7. Andrea M. Matwyshyn, (2011), 'Commentary Discussion of Online Display Advertising: Targeting and Obtrusiveness" by Avi Goldfarb and Catherine Tucker. Marketing Science 30(3):409-412. http://dx.doi.org/10.1287/mksc.1100.0599

8. Armo Kuisma, Jaana Simola, Liisa Uusitalo \& Anssi Öörni (2010), 'The Effects of Animation and Format on the Perception and Memory of Online Advertising', Journal of Interactive Marketing 24, $269-282$

9. Agarwal, A., K. Hosanagar, M. D. Smith (2011), "Location, location and location: An analysis of profitability of position in online advertising markets," Journal of Marketing Research, 48, 10571073.

10. Perlich C, Dalessandro B, Raeder, T. et al. Mach Learn (2014) 95: 103. doi:10.1007/s10994-013$5375-2$

11. Business Zone (2015), 'The Importance of Digital Marketing', Available at http://www.businesszone.co.uk/community-voice/blogs/tcii/the-importance-of-digital-marketing

12. Comscore (2009), 'Social Networking Sites Account for More than 20 Percent of All U.S. Online Display Ad Impressions', Available at : http://www.comscore.com/Insights/PressReleases/2009/9/Social-Net working-Sites-Account-for-More-than-20-Percent-of-All-U.S.Online-Display-Ad-Impressions-According-to-comScore-Ad-Metrix?cs_edgescape_cc=FI

13. Christian Maurer, Rona Wiegmann (2011), 'Effectiveness of advertising on social network sites; a case study on Facebook', Chapter: Information and Communication Technologies in Tourism 2011 pp 485-498

14. Dae-Hee Kim, Lisa Spiller, Matt Hettche (2015), 'Analyzing media types and content orientations in Facebook for global brands', Journal of Research in Interactive Marketing, Vol. 9 Iss 1 pp. 4 - 30; Permanent link to this document:http://dx.doi.org/10.1108/JRIM-05-2014-0023

15. David S. Evans ( 2009), 'The Online Advertising Industry: Economics, Evolution, and Privacy, Journal of Economic Perspectives'; Volume 23, Pages 37-60

16. David Meerman Scott. (2010), 'The New Rules of Marketing and PR: How to Use Social Media, Blogs, News Releases, Online Video, and Viral Marketing to Reach Buyers Directly. (2 Ed.). Hoboken, N.J.: John Wiley \& Sons

17. Dong Hoo Kim, Yoon Hi Sung ,So Young Lee, Dongwon Choi ,Yongjun Sung (2016), 'Are you on Timeline or News Feed? The roles of Facebook pages and construal level in increasing ad effectiveness', Computers in Human Behavior; Volume 57 issue C, Pages 312-320 
18. Donna L. Hoffman and Marek Fodor (2010), 'Can You Measure the ROI of Your Social Media Marketing?', MIT Slogan Management Review, Vol.52(1), 41-49

19. Emarketer (2016), 'US Digital Ad Spending to Surpass TV this Year', Available at https://www.emarketer.com/Article/US-Digital-Ad-Spending-Surpass-TV-thisYear/1014469? ecid=NL1003

20. Emarketer (2016), 'Facebook Continues to Grow, Steadily Adding New Revenue Streams', available at https://www.emarketer.com/Article/Facebook-Continues-Grow-Steadily-AddingNew-Revenue-Streams/1013875

21. Emarketer (2016), 'US digital video ad spending will continue to grow at a pace that exceeds TV advertising growth through 2020', available at ttps://www.emarketer.com/Article/Digital-VideoAdvertising-Grow-Annual-Double-Digit-Rates/1014105

22. Farzana Parveen, Noor Ismawati Jaafar, Sulaiman Ainin (2015), 'Social media usage and organizational performance: Reflections of Malaysian social media managers', Telematics and Informatics 32,67-78

23. Feng, Juan, Hemant Bhargava, David Pennock (2007), 'Implementing Sponsored Search in Web Search Engines, Computational Evaluation of Alternative Mechanisms,' INFORMS Journal on Computing, 19 (1), 137-148.

24. Florian Nottorf \& Burkhardt Funk (2013), 'A cross-industry analysis of the spillover effect in paid search advertising', Electron Markets,23:205-216

25. Ginger Rosenkrans (2009) The Creativeness and Effectiveness of Online Interactive Rich Media Advertising, Journal of Interactive Advertising, 9:2, 18-31, DOI:10.1080/15252019.2009.10722152

26. Henry Boateng Abednego Feehi Okoe, (2015),"Consumers' attitude towards social media advertising and their behavioral response", Journal of Research in Interactive Marketing, Vol. 9, Iss 4 pp. $299-312$

27. Hal Varian, Chief Economist Google; Official informational Video by google, available at https://www. youtube.com/watch?v=PjOHTFRaBWA

28. Hensel Kyle, Deis Michael H. (2010), 'Using social media to increase advertising and improve marketing', The Entrepreneurial Executive, Vol 15, 87-97.

29. Hoffman, D. L. (2000), 'The Revolution Will Not Be Televised: Introduction to the Special Issue on Marketing Science and the Internet', Marketing Science, 19(1), 1-3.

30. Ho Seoung Na, Junseok Hwang, Jasmine Yoo Jung Hong, Daeho Lee (2017), 'Efficiency comparison of digital content providers with different pricing strategies', Telematics and Informatics 34,657-663

31. Hongshuang (Alice) Li, P. K. Kannan, Siva Viswanathan, Abhishek Pani (2016), 'Attribution Strategies and Return on Keyword Investment in Paid Search Advertising'. Marketing Science, $831-848$ 
32. Hsu-Hsien Chi (2011), 'Interactive Digital Advertising vs.Virtual Brand Community', Journal of Interactive Advertising, 12:1, 44-61, DOI:10.1080/15252019.2011.10722190

33. Internetlivestats.com (2017), Internet Users, available at http://www.internetlivestats.com/internet-users/

34. J. Ken Corley II \& Zack Jourdan \& W. Rhea Ingram (2013), 'Internet marketing: a content analysis of the research', Electron Markets 23:177-204

35. Jarmo Kuisma, Jaana Simola,Liisa Uusitalo, Anssi Öörni (2010), 'The Effects of Animation and Format on the Perception and Memory of Online Advertising', Journal of Interactive Marketing. $24,269-282$.

36. Jason T. Jacques, Mark Perry, Per Ola Kristensson (2015), 'Differentiation of online text-based advertising and the effect on users' click behavior', Computers in Human Behavior 50 535-543

37. Janice Penni (2016), 'The future of online social networks (OSN): A measurement analysis using social media tools and application', Telematics and Informatics, In Press

38. Jeff Green (2012), 'Define It - What Is Real-Time Bidding; Adexchange', available at https://adexchanger.com/online-advertising/real-time-bidding/

39. Javad Azimi,Ruofei Zhang, Yang Zhou (2012), 'The Impact of Visual Appearance on User Response in Online Display Advertising', WWW 2012 Companion, April 16-20, 2012, Lyon, France;ACM 978-1-4503-1230-1/12/04.

40. Jing Zhang, En Mao (2016), 'From Online Motivations to Ad Clicks and to Behavioral Intentions: An Empirical Study of Consumer Response to Social Media Advertising', Psychology \& Marketing, Vol. 33(3): 155-164

41. Jiyoung Cha (2013), 'Predictors of television and online video platform use: A coexistence model of old and new video platforms', Telematics and Informatics 30, 296-310

42. Joonghwa Lee, Mikyoung Kim, Chang-Dae Ham \& Soojung Kim (2016), 'Do you want me to watch this ad on social media? The effects of norms on online video ad watching', Journal of Marketing Communications, 1-17, http://dx.doi.org/10.1080/13527266.2016.1232303

43. Johannes Knoll (2016), 'Advertising in social media a review of empirical Evidence', International Journal of Advertising, 35:2, 266-300

44. Joowon Lee, Jae-Hyeon Ahn, Byungho Park (2013), 'The effect of repetition in Internet banner ads and the moderating role of animation' Volume 46, Pages 202-209 http://dx.doi.org/10.1016/j.chb.2015.01.008

45. Joe Phua, Seunga Venus Jin, Jihoon Kim (2017), Gratifications of using Facebook, Twitter, Instagram, or Snapchat to follow brands: The moderating effect of social comparison, trust, tie strength, and network homophily on brand identification, brand engagement, brand commitment, and membership intention', Telematics and Informatics 34 , 412-424 
46. Kai-Yu Wang, Eric Shih \& Laura A. Peracchio (2013), 'How banner ads can be effective, International Journal of Advertising', 32:1, 121-141; http://dx.doi.org/10.2501/IJA-32-1-121-141

47. Kang Li , Guanxiong Huang, Gary Bente (2015), 'The impacts of banner format and animation speed on banner effectiveness: Evidence from eye movements', Computers in Human Behavior, $522-530$

48. Kelly, L., G. Kerr, and J. Drennan (2010), 'Avoidance of advertising in social networking sites. The teenage perspective', Journal of Interactive Advertising 10, no. 2: pp.16-27.

49. Kinshuk Jerath, Liye Ma, and Young-Hoon Park (2014), 'Consumer Click Behavior at a Search Engine: The Role of Keyword Popularity’, American Marketing Association, Vol. LI (August 2014), 480-486

50. Kotler P. (1984), 'Marketing Essentials / Northwestern University. Prentice-Hall, Inc.

51. Kuisma, J., Simola, J., Uusitalo, L., \& Oorni, A. (2010), 'The effects of animation and format on the perception and memory of online advertising', Journal of Inter-active Marketing, 24(4), 269.

52. Li Ji, Pan Rui \& Wang Hansheng (2010), 'Selection of Best Keywords, Journal of Interactive Advertising, 11:1, 27-35;Article link: http://dx.doi.org/10.1080/15252019.2010.10722175

53. Lili Shan, Lei Lin, Chengjie Sun, Xiaolong Wang (2016), 'Predicting ad click-through rates via feature-based fully coupled interaction tensor factorization', Journal of Electronic Commerce Research and Application; Volume 16 Issue C, Pages 30-42

54. Linnea Hansson, Anton Wrangmo \& Klaus Solberg Søilen (2013), 'Optimal ways for companies to use Facebook as a marketing channel', Journal of Information, Communication and Ethics in Society 11 (2):112-126 (2013)

55. Louise Kelly, Gayle Kerr \& Judy Drennan (2010), ‘Avoidance of Advertising in Social Networking Sites, Journal of Interactive Advertising', 10:2, 16-27, DOI:

10.1080/15252019.2010.10722167

56. Mark Brown (2002), 'The Use of Banner Advertisements with Pull-Down; Journal of interactive advertising', Pages 57-65

57. Maria Teresa Pinheiro Melo Borges Tiago, Jose' Manuel Cristo'va oo Verı́ssimo (2014), 'Digital marketing and social media: Why bother? Business Horizons, 57, 703-708

58. Mariea Grubbs Hoy \& George Milne (2010), ‘Gender Differences in Privacy-Related Measures for Young Adult Facebook Users', Journal of Interactive Advertising, 10:2,28-45, DOI: 10.1080/15252019.2010.10722168

59. Michaelidou, N., Siamagka, N., \& Christodoulides, G. (2011), 'Usage, barriers and measurement of social media marketing: An exploratory investigation of small and medium B2B, brands', Industrial Marketing Management, 40, 1153-1159.

60. Nadia Abou Nabout \& Bernd Skiera (2012), 'Return on Quality Improvements in Search Engine Marketing', Journal of Interactive Marketing, 26,141 - 154 
61. Nadia Abou Nabout , (2015),"A novel approach for bidding on keywords in newly set-up search advertising campaigns", European Journal of Marketing, Vol. 49 Iss 5/6 pp. 668 - 691 Permanent link to this document: http://dx.doi.org/10.1108/EJM-08-2013-0424

62. Nadia Abou Nabout, Bernd Skiera, Tanja Stepanchuk, Eva Gerstmeier (2012), 'An analysis of the profitability of fee-based compensation plans for search engine marketing, Intern. J. of Research in Marketing 29,68-80

63. Nadia Pomirleanu, John A. Schibrowsky, James Peltier, Alexander Nill, (2013),"A review of internet marketing research over the past 20 years and future research direction", Journal of Research in Interactive Marketing, Vol. 7 Iss 3 pp. 166 - 181,Permanent link to this document: http://dx.doi.org/10.1108/JRIM-01-2013-0006

64. Ngai, E.W.T. (2003), 'Internet marketing research (1987-2000): a literature review and classification”, European Journal of Marketing', Vol. 37 Nos 1/2, pp. 24-49.

65. Nina Michaelidou, Nikoletta Theofania Siamagka, George Christodoulides (2011), 'Usage, barriers and measurement of social media marketing: An exploratory investigation of small and medium B2B brands', Industrial Marketing Management 40 (2011) 1153-1159

66. Oliver J. Rutz, Michael Trusov, Randolph E. Bucklin (2011), 'Modeling Indirect Effects of Paid Search Advertising: Which Keywords Lead to More Future Visits?', Marketing Science 30(4):646-665. http://dx.doi.org/10.1287/mksc.1110.0635

67. Palmer, A. and Koenig-Lewis, N. (2009), 'An experimental, social network-based approach to direct marketing', Direct marketing, An International Journal, Vol. 3 No. 3, pp. 162-176.

68. Rodney Graeme Duffett, (2015), 'Facebook advertising's influence on intention-to-purchase and purchase amongst Millennials', Internet Research, Vol. 25 Iss 4 pp. 498 - 526; Permanent link to this document:http://dx.doi.org/10.1108/IntR-01-2014-0020

69. Rutz, O. J., \& Bucklin, R. E. (2011), 'From generic to branded: a model of spillover in paid search advertising', Journal of Marketing,Research, 48(1), 87-102

70. Schibrowsky, J.A., Peltier, J.W. and Nill, A. (2007), 'The state of internet marketing research: a review of the literature and future research directions', European Journal of Marketing, Vol. 41 No. 7 , pp. 722-733.

71. Sebastian Klapdor \& Eva M. Anderl \& Florian von Wangenheim \&\& Jan H. Schumann (2014), 'Finding the Right Words: The Influence of Keyword Characteristics on Performance of Paid Search Campaigns', Journal of Interactive Marketing 28285 - 301

72. Sha Yang, Shijie Lu, Xianghua Lu (2014) Modeling Competition and Its Impact on Paid-Search Advertising. Marketing Science 33(1):134-153. http://dx.doi.org/10.1287/mksc.2013.0812

73. Shuai Yuan, Jun Wang, Xiaoxue Zhao (2013),' ‘ Real-time Bidding for Online Advertising: Measurement, and Analysis' ADKDD '13, Chicago, Illinois, U.S.A

74. Shalinda Adikari and Kaushik Dutta (2015), 'Realtime Bidding in Online Digital Advertisement', Springer International Publishing, pp. 19-38, 2. DOI: 10.1007/978-3-319-18714-3_2 
75. Shuai Yang, Shan Lin, Jeffrey R. Carlson \& William T. Ross Jr. (2016) 'Brand engagement on social media: will firms' social media efforts influence search engine advertising effectiveness?', Journal of Marketing Management, 32:5-6, 526-557, DOI:10.1080/0267257X.2016.1143863

76. Sridhar Narayanan, Kirthi Kalyanam (2015), 'Position Effects in Search Advertising and their Moderators: A Regression Discontinuity Approach', Marketing Science 34(3):388-407. http://dx.doi.org/10.1287/mksc.2014.0893

77. Sungchul Kim, Tao Qin, Tie-Yan Liu, Hwanjo Yu (2014), 'Advertiser-centric approach to understand user click behavior in sponsored search, Information Sciences, 242-254

78. Tat Y. Chan, Young-Hoon Park (2015), 'Consumer Search Activities and the Value of Ad Positions in Sponsored Search Advertising', Marketing Science 34(4):606-623. http://dx.doi.org/10.1287/mksc.2015.0903

79. Weinan Zhang, Shuai Yuan, Jun Wang (2014), 'Optimal Real-Time Bidding for Display AdvertisingKDD'14, August 24-27, 2014, New York, NY, USA. http://dx.doi.org/10.1145/2623330.2623633,2014

80. Wenhong Luo,David Cook,Eric J.Karson (2011), 'Search advertising placement strategy: Exploring the efficacy of the conventional wisdom, Information \& Management 48, 404-411

81. Frobes (2015), 'What Is Google RankBrain And Why Does It Matter?', available at http://www.forbes.com/sites/jaysondemers/2015/11/12/what-is-google-rankbrain-and-why-doesit-matter/\#628fb7d0301a

82. Wilfred Amaldoss, Kinshuk Jerath, Amin Sayedi (2016), Keyword Management Costs and "Broad Match" Advertising. Marketing Science 35(2):259-274. http://dx.doi.org/10.1287/mksc.2015.0919

83. William Flores a, Jeng-Chung Victor Chen, William H. Ross (2013), 'The effect of variations in banner ad, type of product, website context, and language of advertising on Internet users' attitudes, Computers in human behavior 31, 37-7, http://dx.doi.org/10.1016/j.chb.2013.10.006

84. Woochoel Shin (2015), 'Keyword Search Advertising and Limited Budgets' Marketing Science 34(6):882-896. http://dx.doi.org/10.1287/mksc.2015.0915

85. Xianghua Lu \& Xia Zhao (2014), 'Differential Effects of Keyword Selection in Search Engine Advertising on Direct and Indirect Sales', Journal of Management Information Systems, 30:4, 299-326

86. Yang, Anindya Ghose, (2010), 'Analyzing the Relationship between Organic and Sponsored Search Advertising: Positive, Negative, or Zero Interdependence?' Marketing Science 29(4):602623. http://dx.doi.org/10.1287/mksc. 1090.0552 


\section{Highlights}

- Digital advertising literature revolves around IAPS in three basic domains 1) search engine advertising 2) social media advertising 3) display advertising

- These categories are mutually independent; from an industry point of view, campaign mechanics, payment method, audience selection, and results differ across categories, with different managerial yield

- Most of the literature of digital advertising revolves around IAPS but without naming it

- For Search Engine Marketing, previous studies have focused on keyword selection, bidding strategy, and search engine ad ranking systems

- The scarcity of academic studies on social media in relation to IAPS hinders nuanced understanding. Much of the available literature reports unfavorable responses to social media advertising in social networks

- Programmatic buying and RTB is the future of display advertising 